\title{
Social Skills and Resilience in Adolescents of an Educational Institution in North Lima, 2019
}

\author{
Lili Sifuentes-Gomez ${ }^{1}$, Doris Vega-Davila ${ }^{1}$, Betty Flores-Paz ${ }^{1}$, Brian Meneses-Claudio ${ }^{2,}$, Hernan Matta-Solis ${ }^{1}$, Eduardo Matta-Solis ${ }^{3}$ \\ ${ }^{1}$ Faculty of Health Sciences, Universidad de Ciencias y Humanidades, 15314, Lima-Perú \\ ${ }^{2}$ Image Processing Research Laboratory (INTI-Lab), Universidad de Ciencias y Humanidades, 15314, Lima-Perú \\ ${ }^{3}$ Research and Intellectual Creativity Direction, Universidad María Auxiliadora, 15408, Lima-Perú
}

\begin{tabular}{l} 
A R T I C L E I N F O \\
\hline Article history: \\
Received: 03 August, 2020 \\
Accepted: 25 November, 2020 \\
Online: 16 December, 2020 \\
\hline Keywords: \\
Social Skills \\
Resilience \\
Educational institution \\
Daily Life \\
Coping
\end{tabular}

\section{Introduction}

Social skills or assertive behaviors are understood as a set of partially independent and situationally specific verbal and nonverbal responses, through which adolescents express in an interpersonal their needs, feelings, preferences, right opinions without excessive anxiety and in a non-aversive way, expressing itself in self-expression of social situations, defense of its own rights as a consumer, expression of anger or disagreement, saying no and cutting interactions, initiating positive interactions with the opposite sex and making requests. Social skills are involved in many areas of a person's life, such as adaptation to the environment in which they live and health protection, both physical and mental. It helps to solve various situations such as appropriateness in behavior, decision making, facing difficult situations, assigned essential responsibilities in the development of learning [1].

\footnotetext{
*Corresponding Author: Brian Meneses-Claudio, Mr., +51 1950159924 \& bmeneses@uch.edu.pe
}

Regarding resilience, it is the set of qualities, resources or strengths that favor adolescents to face life's adversities, overcome them or even be transformed by it, which is characterized by presenting traits of persistence-tenacity-selfefficiency, control under pressure, adaptation and support environments, control and purpose and spirituality [2].

Social skills and resilience can prevent problems that may affect adolescents in their daily life, where risky conditions such as family problems, drug abuse or abandonment make it evident that resilient factors are looking for a way to excel in risky conditions in an adolescent-friendly way [3], [4].

Therefore, social skills and resilience play an important role in the adolescent since it will allow them to develop on a social and emotional level so that they can adapt to their environment and at the same time they can face adverse situations in their daily life $[5]$.

In Peru, according to the report of the Instituto Nacional de Estadística e Informática, $32.9 \%$ of households are made up of 
girls and boys and/or adolescents, of whom there is at least one child under 18 with a caloric deficit, being higher in rural areas $(33.5 \%)$ than in urban areas $(33.2 \%)$ and Metropolitan Lima $(32.0 \%)$. On the other hand, $41.4 \%$ of children under 18 years of age had a problem that affected their health such as a new disease, a relapse or an accident. Health problems occurred more frequently in children and adolescents in the urban area, not including Metropolitan Lima (42.5\%), Metropolitan Lima (41.4\%) and rural areas (39.8\%) [6].

In [7], the authors presented a research work carried out in Colombia, significant differences were shown in emotional intelligence. In the high social acceptance group, low scores were found in the social skills evaluated, being the ability to make requests lower. Likewise, statistically significant correlations were found between several of the factors of the Baron test and those of the Social Skills Scale.

In [5], the authors described a study carried out in Spain, in the sample made up of 844 participants of both sexes, it shows that the most resilient adolescents have better results in all dimensions of quality of life and the effect of resilience is greater in the dimensions related to mental health and in all those that measure social relationships.

In [3], the authors described a study carried out in Colombia, a study was presented regarding the ability to listen, the ability to start a conversation, the ability to hold a conversation and the ability to ask for help, it is evident that most of people obtained scores between high and medium level. On the other hand, in the expression subscale of feelings, it is stated that most men have a medium level, while women are between the medium level and a high level.

The objective of the study is to determine the social skills and resilience in adolescents of an educational institution in North Lima in which it will allow to give important data about the social skills and resilience of adolescent students at the secondary level because nowadays, adolescents tend to have little communication with others in which this behavior cannot help them in a social situation effectively.

The study applied the data collection instrument Social Skills Scale (SSS), it was created by Elena Gismero Gonzales and the Connor-Davidson Resilience Scale (CD-RISC), which has been useful to assess social skills and resilience of adolescents at the secondary level of an educational institution.

The data collection was processed through the survey of adolescents at the secondary level, the data was entered in a data matrix that will be designed in the statistical program SPSS (Statistical Package for the Social Sciences) in its version 24.0, in which it will allow a better data processing to make statistical tables and graphs so that they can be described and interpreted in results and discussions, respectively.

The following research work is structured as follows: In section II, the development of data collection processing for each adolescent at the secondary level will be presented, as well as the guidelines to consider so that they are included in the research work. In section III, the results will show the social skills and resilience of adolescents at the secondary level of the educational institution according to the specified dimensions of the instruments in the measurement of the variables. In section IV, it presents the discussions of the research work, in section $\mathrm{V}$, the conclusions and in section VI the recommendations as well as the future work that is intended to be reached with the research work.

\section{Methodology}

In this section, the type and design of the research will be evidenced, as well as the population and sample that will be carried out in the research work, in addition to the inclusion and exclusion criteria and finally the technique and the instrument of data collection.

\subsection{Research Type and Design}

The present research is non-experimental, descriptive of a quantitative approach, it is a cross-sectional correlational research.

\subsection{Population and sample}

The population is made up of 706 students from 1st to 5 th secondary level of the educational institution 3049 Imperio Del Tahuantinsuyo.

\section{Inclusion Criteria}

- Students who normally attend the educational institution.

- Students who have informed consent and assent.

- Students who have the authorization signed by their parents and agree to voluntarily join the study.

\section{Exclusion Criteria}

- Students who do not regularly attend to the institution.

- Students who do not have the authorization of their parents.

\subsection{Technique and instrument}

The technique used is the survey, using the questionnaire or instrument for collecting data on social skills and resilience, which aims to measure social skills and resilience in adolescents of an educational institution in North Lima.

The Social Skills Scale (SSS) was created by Elena Gismero Gonzales, from the Universidad Pontificia de Comillas (Madrid) in 1997, its application is given individually and collectively, with an approximate duration of 10 to 15 minutes, it is focused in adults and adolescents. The social skills scale consists of 33 items grouped into 6 dimensions, self-expression in social situations $(8$ items), defense of one's rights as a consumer (5 items), expression of anger or disagreement (4 items), saying do not cut off interactions ( 6 items), make requests ( 5 items) and initiate positive interactions with the opposite sex (5 items) that are evaluated by a Likert-type scale where " 1 = I do not identify myself, in most times it does not happen to me or it does not I would do " " 2 = it has nothing to do with me, even if it happens to me sometime" ", 3 $=$ describes me roughly, even if I don't always act that way or feel that way "and" $4=$ strongly agree, I would feel that way or act that way in most cases". The scale range varies from 33 to 132, the higher the score, the higher the adolescent's social skills [8].

The Connor-Davidson Resilience Scale (CD-RISC) was built by Connor and Davidson in the United States in 2003. 
Its application is focus for the adolescent and adult population from 11 to 80 years old, the resilience scale consists of 25 items grouped into 5 dimensions, persistence-tenacity-self-efficacy $(8$ items), control under pressure (7 items), adaptation and ability to recover (5 items), control and purpose (3 items) and spirituality (2 items) that are evaluated with a Likert-type scale where " $0=$ never", "1 = rarely", " $2=$ sometimes", " $3=$ often" and " $4=$ almost always". The range of the scale varies from 0 to 100 , the higher the score, the higher the resilience in the adolescent [9].

\subsection{Place and Application of the Instrument}

The survey to measure social skills and resilience in adolescents was carried out at the 3049 educational institution of Imperio del Tahuantinsuyo in North Lima.

The survey was carried out in two consecutive shifts, morning and afternoon according to the schedule of the students of the secondary level, the questionnaire was taken to the secondary level students with a time of 20 minutes to each selected section (1st from high school to 5th grade according to the inclusion criteria), it was concluded with a good satisfaction at the time of collecting the surveys since support from high school students was presented to carry out this research work.

It is very important to emphasize the presence of classroom teachers at the time of completing the surveys, because this helps students to relay on making questions using the sign of upper hand. In addition to the presence of nursing professionals since the mental health of adolescents is very important, because they are the future where the ways of communication tend to be high and that allow them to generate self-confidence and be able to perform effectively to any situation that is happening.

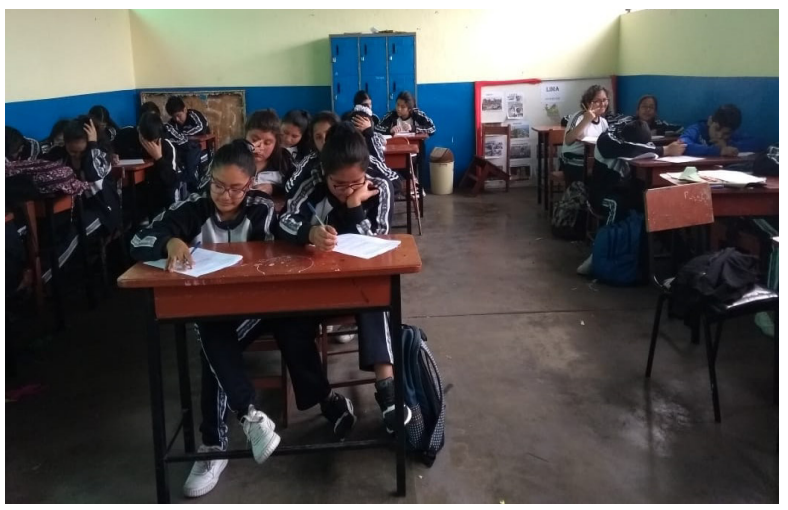

Figure 1: Application of the Survey to the students of the Educational Institution

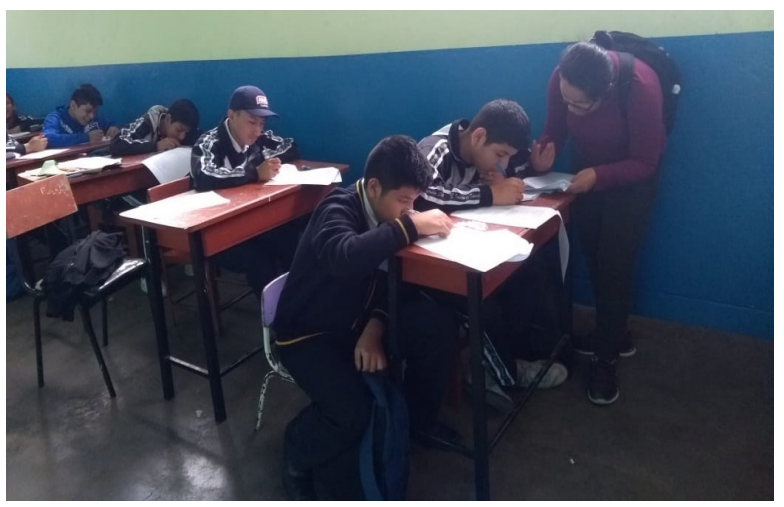

Figure 2: Nursing staff is supporting in carrying out the survey
In Figure 1, the resolution of survey is shown in a classroom of the educational institution at the secondary level by the students, the collaboration of the students can be seen since this allows interaction with them.

In Figure 2, the reader can see the direct interaction with the adolescent student for the research process, it should be noted that the students gave confidence when explaining about the completion of the surveys.

\section{Results}

The table 1 is a summary of the surveys carried out following the guidelines corresponding to the research work:

Table 1: Social Skills and Resilience in secondary level students of Independencia Educational Institution - North Lima, $2019(\mathrm{~N}=706)$

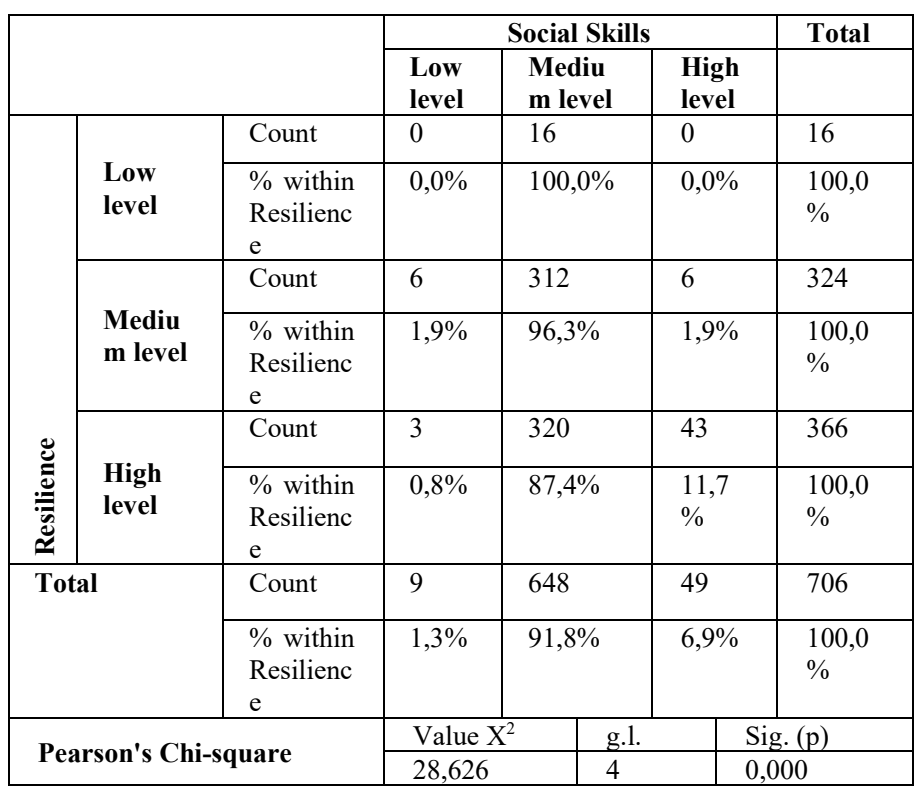

The significance level of the test obtained a value of $0.000(\mathrm{p}$ $<0.05)\left(X^{2}=28.626\right.$; g.l. $\left.=4\right)$. This indicates that there is a significant relationship between social skills and resilience.

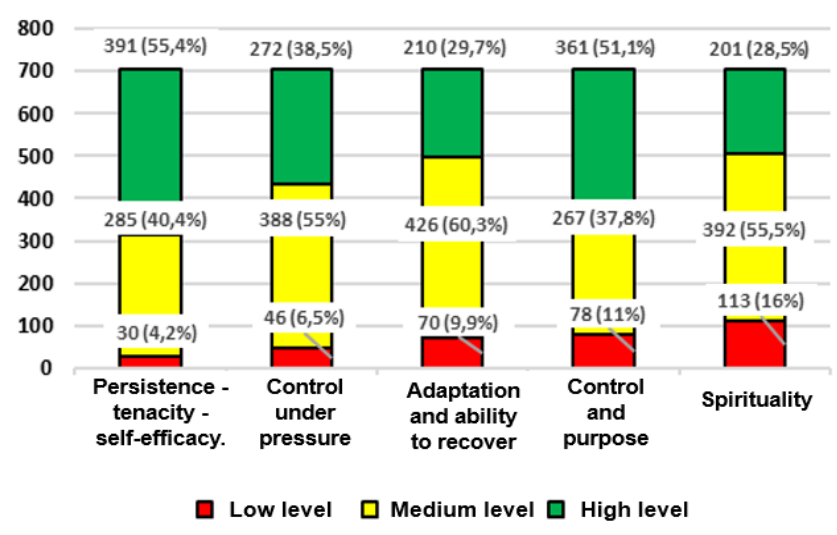

Figure 3: Social skills according to their dimensions in secondary level students in an Educational Institution of Independencia - North Lima, $2019(\mathrm{~N}=706)$

In Table 2, it can see the social skills in secondary level students in an Educational Institution of Independencia - North Lima, where the middle level predominates with $648(91.8 \%)$ students. 
Table 2: Social Skills in secondary level students in an Educational Institution of Independencia - North Lima, $2019(\mathrm{~N}=706)$

\begin{tabular}{|l|l|l|l|}
\hline \multicolumn{2}{|c|}{} & $\mathbf{N}$ & $\%$ \\
\hline \multirow{3}{*}{ Social Skills } & Low Level & 9 & 1,3 \\
\cline { 2 - 4 } & $\begin{array}{l}\text { Medium } \\
\text { Level }\end{array}$ & 648 & 91,8 \\
\cline { 2 - 4 } & High Level & 49 & 6,9 \\
\hline Total & & 706 & 100,0 \\
\hline
\end{tabular}

In Figure 3, it can observe social skills according to their dimensions, where the most affected dimension was the expression of anger or disagreement with 97 (13.7\%) students.

Table 3: Resilience in secondary level students in an Educational Institution of Independencia - North Lima, $2019(\mathrm{~N}=706)$

\begin{tabular}{|l|l|l|l|}
\hline \multicolumn{2}{|c|}{} & N & \% \\
\hline \multirow{3}{*}{ Resilience } & Low Level & 16 & 2,3 \\
\cline { 2 - 4 } & $\begin{array}{l}\text { Medium } \\
\text { Level }\end{array}$ & 324 & 45,9 \\
\cline { 2 - 4 } & High Level & 366 & 51,8 \\
\hline Total & & 706 & 100,0 \\
\hline
\end{tabular}

In Table 3, it can see the resilience of secondary level students in an Educational Institution of Independence, where the high level predominated with 366 (51.8\%) students.

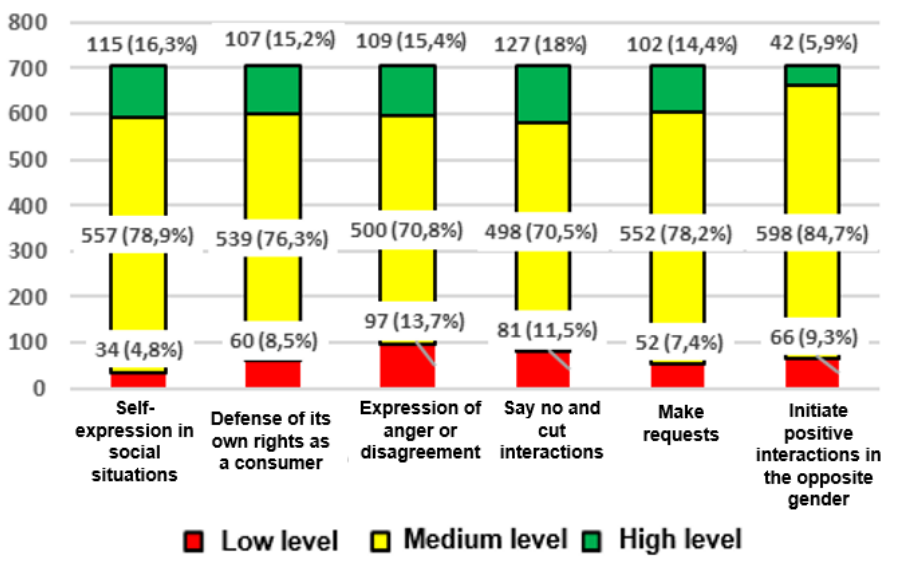

Figure 4: Resilience in secondary level students in an Educational Institution of Independence - North Lima, 2019 (N = 706)

In Figure 4, it can see the resilience according to its dimensions in secondary level students in an Educational Institution of Independence, where the most affected dimension was spirituality with $113(16 \%)$ students.

Both studies can be interpreted that social skills and resilience in adolescents are linked to the promotion of mental and physical health of adolescents, knowing that resilience is relevant because it will allow the person to respond appropriately to negative events or situations. It also focuses on social skills because it is an essential element to achieve the socio-emotional development of the human being and favors school learning. It is vitally important to develop social skills and have a high level of resilience, but unfortunately there is a knowledge gap, reviewing the scientific information related to this topic.

These results will help to the educational institution since it will provide them with information that will allow to evaluate more concisely the adolescents of the secondary level, giving importance to the mental health of the student, in which it is beneficial for them and so they can communicate in an appropriate way that allows to have opportunities in the future.

\section{Discussion}

In the present study, the issue of social skills and resilience is raised from the point of view of promoting adolescent health, which seeks to contribute to institutions that are in the educational field as part of comprehensive adolescent training, including programs that allow adolescents to enhance their ability to interact, be extrovert, and cope with problems to improve their social life.

Based on the social skills in adolescents of the educational institution 3049 Imperio del Tahuantinsuyo, it prevailed in medium level followed by high and low. These results are based on two purposes: the first, if there are no interventions in the group with a medium level of social skills, these will not have a full development their personality. On the other hand, making interventions can raise the level of social skills, which would be beneficial for adolescent development. In [10], the authors showed that adolescents are normally receptive to new ideas, and are eager to take full advantage of their growing capacity to make decisions; their curiosity and interest lead to a great openness to new possibilities and among them could be considered relating to their peers. Engaging in positive and constructive activities offers opportunities to build relationships with adults and peers. The reason for these findings is due to the fact that in the institution there are no teachers prepared for the tutoring course, they are the teachers of different courses who are in charge of some sections and the participation of parents in the meetings is required.

By implementing well-designed social skills programs, the level of social skills can be raised for the benefit of adolescents and mental health. In these processes of strengthening social skills, the family must also be involved, since this constitutes an important Socialization space and parents play an important role as Trainers and counselors. Conditions must be implemented in schools such as not saturating student classrooms and having the necessary infrastructure for the work of the teacher and tutor; favoring the work of professionals for the benefit of adolescents [11].

Regarding social skills in its self-expression dimension in social situations in adolescents of the educational institution 3049 Imperio del Tahuantinsuyo-Independencia 2019, the medium level prevailed followed by the high and low. It reflects the ability of each individual to express themselves spontaneously in different social and work events. We agree with what was stated by Pérez, who points out in its study that an institutional intervention program can significantly improve social skills in adolescents. 
Regarding to social skills in their defense of their rights as a consumer dimension in adolescents of the educational institution 3049 Imperio del Tahuantinsuyo-Independencia 2019, the medium level prevailed followed by the high and the low. Obtaining a high score reflects the expression of assertive behavior towards strangers in defense of their own rights in situations of consumption. Regarding social skills in their dimension defending their own rights as consumers in adolescents from a pre-university center in Lima Norte, the medium level predominated, followed by the low and high. This dimension is related to being an active participant in social life that allows to exercise full citizenship. In [12], the author deduces in his study that the development of social skills and their dimensions, play a protective role for the adolescent, away from risky doings and behaviors such as marijuana use.

Regarding to social skills in its expression of anger or disagreement dimension in adolescents from the educational institution 3049 Imperio del Tahuantinsuyo-Independencia. 2019, the medium level prevailed followed by the high and low. It rates the individual's ability to handle their conflicts with another person in a negative or positive way. In [13], the authors point out from the findings of their study, that the training institution must assume a leading role in promoting social skills; teachers play an important role, so they must be permanently trained to join and contribute to the promotion of social skills in them.

In relation to social skills in it say no and cut interactions dimension in adolescents of the Educational Institution 3049 Imperio del Tahuantinsuyo-Independencia 2019, the medium level prevailed followed by the low and high. This dimension reflects the ability of the individual to cut off interactions that they do not want to maintain, as well as refusing to lend something when dislike doing so, it was found that the vulnerable adolescents who are victims of bullying do not know how to respond to these situations and they have a hard time saying "enough" or "not".

Respecting of social skills in its making requests dimension in adolescents from the educational institution 3049 Imperio del Tahuantinsuyo-Independencia 2019, the medium level prevailed followed by the low and high. This dimension reflects the ability of the individual to make a request without difficulties, it should be noted that in cooperative learning processes they promote the development of social skills and can enhance the ability to make requests in an appropriate and timely manner.

Regarding social skills in its dimension, initiating positive interactions with the opposite sex in adolescents from the educational institution 3049 Imperio del TahuantinsuyoIndependencia 2019, the medium level prevailed followed by the low and high [10]. This dimension qualifies the ability of the individual to relate, interact with the opposite sex. This dimension presented a higher percentage in the low level of social skills.

Concerning the level of resilience in adolescents of the educational institution 3049 Imperio del TahuantinsuyoIndependencia 2019, the high level predominated, followed by a minimal difference from the medium and low level. The results would be explained in different ways, one of the advantages is that the highest percentage lives with their parents, they share family experiences, which favors them as a protective factor so that they can overcome adversities and get out with great ease. The adolescence plays a very important role in resilience since at this stage of life, it goes through various changes such as: biological, psychological and social. This is where most conflicts, rebellions are generated, testing their ability to adapt [12].

In relation to its spiritual dimension, it has a higher percentage in the low level of resilience. The role of spirituality in improving an adolescent's ability to cope with stressful life situations is often under-appreciated, especially in the context of mental health services within a juvenile detention environment.

\section{Conclusions}

We can conclude that social skills and resilience are mutually related since both allow adolescents to develop functions that allow them to have resources or strengths to cope with situations of daily life.

It is concluded that the social skills are very important for adolescents since it is fundamental for their daily life because they can get success, have proper communication with other people and not only of verbally as well as affectively and emotionally.

It is concluded that resilience is very favorable for adolescents since, within their social environment, they will have the capacity to solve stressful situations and will make them vulnerable to any situation, since resilience will allow adolescents to adapt to these situations and be able to solve them effectively.

\section{Recommendations}

It is recommended in this institution to have programs that help improve communication between the students themselves so that they can improve their communication with other people.

It is recommended in this institution that it be carried out annually with a control system on social skills and resilience since these are essential for the adolescents so this will allow them to communicate with society and also with their environment.

It is also recommended that health professionals attend educational institutions where they can observe certain deficiencies in social skills and resilience in order to allow them to carry out psycho-affective programs where the adolescent can interact with their social environment and also develop both verbal and non-verbal skills.

\section{Conflicts of Interest}

The authors declare no conflict of interest.

\section{References}

[1] R. Estrada, E. Escoffié, R. García, "Habilidades sociales en adolescentes institucionalizados: Una intervención con juego grupal.," Psicumex, 6(2), 27-38, 2016, doi:10.36793/psicumex.v6i2.285.

[2] A. Rodríguez, E. Ramos, I. Ros, A. Fernández, L. Revuelta, "Bienestar subjetivo en la adolescencia: el papel de la resiliencia, el autoconcepto y el apoyo social percibido.," Suma Psicologica, 23(1), 60-69, 2016, doi:10.1016/j.sumpsi.2016.02.002.

[3] S. Betancourth, C. Zambrano, A. Ceballos, V. Benavides, N. Villota, "Habilidades sociales relacionadas con el proceso de comunicación en una muestra de adolescentes.," Psicoespacios, 11(18), 133, 2017, doi:10.25057/21452776.898.

[4] C. Huang, Y. Chen, S. Cheung, L. Greene, S. Lu, "Resilience, emotional problems, and behavioural problems of adolescents in China: Roles of mindfulness and life skills.," Health and Social Care in the Community, 1- 
9, 2019, doi:10.1111/hsc.12753.

[5] M. Simón, R. Fuentes, M. Garrido, M. Serrano, E. Larrañaga, S. Yubero, "Influencia de la resiliencia sobre la calidad de vida relacionada con la salud en adolescentes.," Enfermería Clínica, 28(5), 283-291, 2018, doi:10.1016/j.enfcli.2018.06.003.

[6] Instituto Nacional de Estadistica e Informatica, Estado de la Niñez y Adolescencia., 2018.

[7] C. Coronel, M. Levin, S. Mejail, "Las habilidades sociales en adolescentes tempranos de diferentes contextos socioeconómicos.," Electronic Journal of Research in Educational Psychology, 9(1), 241-261, 2011.

[8] E. Miranda, E. Riquelme, H. Cifuentes, "Revista Latinoamericana de Psicología Análisis factorial confirmatorio de la Escala de habilidades sociales en universitarios chilenos.," Child Psychiatry \& Human Development, 41(2), 73-82, 2010.

[9] G. Guihard, L. Deumier, B. Alliot-Licht, L. Bouton-Kelly, C. Michaut, F. Quilliot, "Psychometric validation of the French version of the ConnorDavidson Resilience Scale.," Encephale, 44(1), 40-45, 2018, doi:10.1016/j.encep.2017.06.002.

[10] M. Valera, L. Buil, E. Rigo, A. Casero, E. Aguilar, "Habilidades sociales en preadolescentes con trastorno específico del lenguaje.," Revista de Logopedia, Foniatria y Audiologia, 36(2), 55-63, 2016, doi:10.1016/j.rlfa.2015.03.002.

[11] E. Maguiña, R. Mino, Facultad De Ciencias De La Salud Escuela Profesional De Enfermería., 2018.

[12] F. Morales, "Relaciones entre afrontamiento del estrés cotidiano, autoconcepto, habilidades sociales e inteligencia emocional.," European Journal of Education and Psychology, 10, 41-48, 2017, doi:10.1016/j.ejeps.2017.04.001.

[13] A. Gonzales, P. Quispe, "Habilidades sociales y rendimiento Académico de los estudiantes de la Facultad de Ciencias de la Educación - Universidad Nacional del Altiplano - Puno Perú.," Revista de Investigaciones Altoandinas - Journal of High Andean Research, 18(3), 331-336, 2016, doi:10.18271/ria.2016.222. 